Filol. Linguíst. Port., São Paulo, v. 17, n. 1, p. 131-155, jan./jun. 2015 http://dx.doi.org/10.11606/issn.2176-9419.v17ilp131-155

\title{
Análise da Conversação e oralidade em textos escritos*
}

\author{
Conversation Analysis and Orality in Written Texts \\ Luiz Antônio da Silva ** \\ Universidade de São Paulo, São Paulo, São Paulo, Brasil
}

\begin{abstract}
Resumo: Marcuschi (1977) ressalta que a oralidade é um importante tópico a ser desenvolvido na sala de aula, mas, infelizmente, tem sido deixado de lado, pois professores e responsáveis pelo ensino não consideram a importância da oralidade no ensino de língua materna. A razão principal é o foco que é dado ao ensino de língua nas escolas brasileiras: a escola existe para ensinar a escrever e escrever bem. Apesar dos avanços dos estudos linguísticos sobre fala e escrita; apesar das contribuiçóes da Sociolinguística e da Análise da Conversação; apesar dos preconceitos vencidos, especialmente sobre a distinção rigorosa entre as duas modalidades, há, ainda, um percurso a vencer. Dessa forma, é produtivo trazer à tona a discussão sobre fala e escrita. Decorridos vários anos da constatação de Marcuschi (1977), autores de livros didáticos, professores, pesquisadores e responsáveis pelo ensino de língua portuguesa têm outra postura teórica, mas, na prática, ainda, há muito que avançar, pois a escrita continua a ser o foco do ensino de língua portuguesa nas escolas brasileiras. Tudo indica que boa parte dos professores conhece a teoria, mas eles têm dificuldades na prática do cotidiano escolar. Este trabalho tem por objetivo analisar marcas de oralidade ou efeitos de oralidade em textos literários escritos, mais precisamente em diálogos produzidos. A partir dessas análises, busca-se dar subsídios ao professor de língua portuguesa, a fim de que ele possa trabalhar de forma coerente e produtiva. Para ilustrar nossas observaçôes, escolhemos fragmentos de crônicas do escritor brasileiro
\end{abstract}

\footnotetext{
* Torno público meu agradecimento à Capes pela concessão de bolsa de estágio sênior na Universidad de Valencia, no período de 2014/2015, durante o qual foi possível pesquisar e escrever este artigo. ** Professor da Área de Filologia e Língua Portuguesa, no âmbito da graduação e da pós-graduação, da Faculdade de Filosofia, Letras e Ciências Humanas da Universidade de São Paulo - USP, São Paulo, São Paulo, Brasil, e pesquisador do Projeto NURC/SP; luizs@usp.br
} 
Luís Fernando Veríssimo, publicadas em três obras: Comédias para se ler na escola, Sexo na cabeça e Amor Veríssimo.

Palavras-chave: Análise da Conversação. Conversaçấo. Oralidade. Ensino de língua.

Abstract: Marcuschi (1977) points out that orality is an important topic to be developed in the classroom. Lamentably, however, it has been left aside, because teachers and those responsible for education do not consider it as an important feature to be emphasized in the mother tongue teaching. The main reason is the focus given to the language teaching in Brazilian schools: the school is supposed to teach writing, and how to write well. Despite the advances of Linguistic studies on speaking and writing; despite the contributions of Sociolinguistics and Conversation Analysis; and despite the overcoming of prejudices, especially on the strict distinction between the two modes, there is still a long way to go. Thus, it is beneficial to bring up a discussion on speaking and writing. After several years of Marcuschi's findings (1977), textbook authors, teachers, researchers and those responsible for the Portuguese language teaching have another theoretical approach. Nonetheless, in practice, there is still a lot to be accomplished since writing continues to be the focus of the Portuguese language teaching in Brazilian schools. It seems that most of the teachers know the theory, but they experience difficulties when it comes to the practices of everyday school life. This paper aims to analyze oral marks or effects of orality in written literary texts, more precisely in dialogues produced. These analyzes will aid us in giving subsidies to a Portuguese teacher, so that he/she can work consistently and productively. To illustrate our observations, we have chosen fragments of chronicles written by Brazilian writer Luís Fernando Verissimo, published in three of his works: Comédias para se ler na escola, Sexo na cabeça and Amor Veríssimo.

Keywords: Conversation Analysis. Conversation. Orality. Language teaching.

\section{CONSIDERAÇÓES INICIAIS}

Este trabalho discute questôes relativas à oralidade e ensino de língua portuguesa. O tema tem sido bastante abordado, especialmente por especialistas ligados 
ao ensino de língua portuguesa e também por aqueles que se dedicam a analisar e avaliar livros didáticos de ensino de língua materna.

Em um trabalho publicado em 1997, Marcuschi ressalta que a oralidade é um importante tópico a ser desenvolvido na sala de aula, mas, infelizmente, tem sido deixado de lado, pois professores e responsáveis pelo ensino não tinham entendido a importância da oralidade no ensino de língua materna. A razão principal, apontada por Marcuschi, é o foco que é dado ao ensino de língua nas escolas brasileiras: a escola existe para ensinar a escrever e escrever bem.

A fala é uma atividade muito mais central do que a escrita no dia a dia da maioria das pessoas. Contudo, as instituiçôes escolares dão à fala atenção quase inversa à sua centralidade na relação com a escrita. Crucial neste caso é que não se trata de uma contradição, mas de uma postura. Seríamos demasiado ingênuos se atribuíssemos essa postura ao argumento de que a fala é táo praticada no dia a dia a ponto de já ser bem dominada e não precisar ser transformada em objeto de estudo na sala de aula. Uma das razóes centrais do descaso pela língua falada continua sendo a crença generalizada de que a escola é o lugar do aprendizado da escrita. Uma crença tão fortemente arraigada que já se transformou numa espécie de consenso: $a$ escola está aí para ensinar a escrita e não a fala. É possível concordar com isto, mas é também possível acrescentar que nem por isso a escola está autorizada a ignorar a fala. O homem é tipicamente um ser que fala e não um ser que escreve. (Marcuschi, 1997, p. 39)

Decorridos vários anos da referida publicação, autores de livros didáticos, professores, pesquisadores e responsáveis pelo ensino de língua portuguesa têm outra postura teórica. O problema reside, justamente, aí: postura teórica. Na prática, ainda, há muito que avançar, pois a escrita continua a ser o foco do ensino de língua portuguesa nas escolas brasileiras. Tudo indica que boa parte dos professores conhece a teoria, mas eles têm dificuldades na prática do cotidiano escolar.

Em outro trabalho sobre questóes referentes à oralidade (Silva, 2009), chamo a atenção para o fato de que a oralidade é a forma primeira e natural da linguagem e que domina nosso cotidiano. Areta Lara (2007, p. 317) lembra que boa parte dos linguistas da segunda metade do século XX, no entanto, dedicou especial atenção à escrita e não à linguagem oral: "Assim, pois, apesar da longevidade da língua falada diante da puerilidade da escrita, esta última tem-se constituído o principal centro de interesse dos estudos linguísticos ao longo de muitas décadas" (Areta Lara, 2007, p. 317). 
No Brasil, a década de 80, com as contribuiçóes da Sociolinguística e da Análise da Conversação, foi um marco no início das mudanças desse quadro. No início do século XXI, Barros (2000) salienta que os atuais estudos linguísticos, que abordam fala e escrita, já não mais apresentam a preocupação de se fazer uma distinção rigorosa entre as duas modalidades, muito menos há a preocupação de salientar as questóes do ponto de vista dicotômico, pois há certo consenso sobre a insuficiência de uma distinção rígida entre escrita e fala e não se duvida da existência de posiçóes intermediárias entre fala e escrita. Hilgert (2000, p. 19), em um ensaio sobre a conversação na internet, ressalta que fala e escrita não se referem a tipos de textos dicotomicamente antagônicos, pois identificam gêneros de textos configurados por um conjunto de traços que os leva a serem concebidos como textos falados ou escritos em maior ou menor grau.

Enfim, com o novo século, no meio acadêmico, houve uma grande preocupação em estabelecer os parâmetros próprios relativos à fala e à escrita. Passada mais de uma década deste novo século, penso que, ainda, seja produtivo trazer à tona a discussão sobre fala e escrita. Sendo assim, este trabalho tem por objetivo analisar marcas de oralidade ou efeitos de oralidade (Barros, 2006 e Hilgert, 2011) em textos literários escritos, mais precisamente em diálogos produzidos. A partir dessas análises, busca-se dar subsídios ao professor de língua portuguesa, a fim de ele possa trabalhar de forma coerente e produtiva.

Para ilustrar nossas observaçóes, escolhemos fragmentos de crônicas do escritor brasileiro Luís Fernando Veríssimo, publicadas em três obras: Comédias para se ler na escola, Sexo na cabeça e Amor Veríssimo.

\section{ENTRE A FALA E A ESCRITA}

Ao abordar as cinco primeiras décadas do século XX, no estudo das relaçóes entre fala e escrita, Marcuschi assim se manifesta:

Houve uma época, e isto vai até os anos 50 do século XX, em que não se tinha um interesse maior pelo problema da relação entre fala e escrita (e muito menos entre oralidade e letramento) na linguística, pois o ideal de ciência estabelecido por Saussure, Bloomfield e ainda hoje por Chomsky não oferece a menor sensibilidade para as questôes envolvidas nos usos (sociais) da língua. Para a linguística oficial é o sistema da língua que está em jogo. (Marcuschi, 2001, p. 26) 
Quando focalizamos os estudos teóricos sobre oralidade e escrita, não podemos deixar de mencionar um dos trabalhos mais importantes de Marcuschi (2001). Fundamentado nos estudos de Wulf Oesterreicher e de Douglas Biber, estabelece a distinção entre oralidade, letramento, fala e escrita. Por oralidade, entende uma prática social interativa para fins comunicativos e que se apresenta sob variados gêneros textuais, fundados na realidade sonora. Letramento envolve as mais diversas práticas de escrita na sociedade em que o indivíduo atribui significados à escrita, ainda que não faça uso formal dela. Por fala, entende uma forma de produção textual-discursiva, situada no âmbito da oralidade, com finalidade comunicativa, com características próprias, como aspectos prosódicos, gestualidade, movimentos do corpo, meneios de cabeça, olhares específicos. Situada no âmbito do letramento, encontra-se a escrita, que é tida como um modo de produção textual-discursiva para fins comunicativos, com certas especificidades: constituição gráfica, recursos pictóricos e etc.

Fala e escrita são duas modalidades pertencentes ao mesmo sistema linguístico. Aliás, Briz Gómez (2004) e Neves (2009) enfatizam que, quando se estudam questôes relativas à fala e à escrita, não se trata de estudar outra gramática, mas considerar toda uma série de fenômenos verbais. Existem diferenças estruturais, pois diferem no modo de aquisição, nas condições de produção, transmissão, recepção e uso. No referido trabalho de Marcuschi (2001), as relaçóes entre fala e escrita, são abordadas a partir da noção de um continuum entre os polos da fala e da escrita em termos de gêneros textuais. Nesse continuum, há, de um lado, o extremo da oralidade e, de outro, o extremo da escrita. Sendo assim, a conversação espontânea está em um polo extremo em comparação com um ensaio acadêmico. O primeiro representa o gênero prototípico da fala e o segundo, o gênero prototípico da escrita. Nesse continuum, um discurso acadêmico, embora seja um texto falado do ponto de vista de sua realização fônica, é, conceptualmente, um texto escrito. Já uma carta pessoal para um amigo íntimo, ainda que se realize por escrito, aproxima-se, conceptualmente, de um texto falado.

Koch e Oesterreicher (2013[1985]) e Oesterreicher (1986) apresentam uma nova terminologia para a análise das questóes referentes à fala e escrita: oralidade e escrituralidadel. Como parâmetro para a classificação dos diversos tipos de textos, os autores distinguem duas perspectivas fundamentais. A primeira refere-se ao meio de comunicação, isto é, a diferença entre a realização fônica / sonora de um enunciado e sua manifestação gráfica. A manifestação verbal que utiliza o meio fônico pode ser chamada de "língua falada", enquanto aquela que

1 Optei por conservar o termo proposto na obra de Oesterreicher, ainda que seja um neologismo, pelo fato de fazer correspondência com oralidade e, especialmente, por náo confundir com escrita. 
utiliza o meio gráfico é a "língua escrita". A segunda refere-se à concep̧̧ão ${ }^{2}$ e, de acordo com Hilgert (2000, p. 19), diz respeito às condiçôes de comunicação e às estratégias adotadas para a sua formulação. Assim, um determinado texto pode estar situado no campo da imediatez comunicativa ou da distância comunicativa. Urbano (2006) explica tal diferença.

Para nós, imediatez se refere à comunicação imediata no tempo e no espaço, ao passo que a distância compreende a comunicação, cuja recepçáo é independente do momento e do lugar de sua produçáo. A imediatez representa, pois, uma comunicação imediata, face a face e em tempo real. Por outro lado, podemos interpretar, mais ou menos com Marcuschi, que imediatez de um lado e distância do outro têm certa equivalência com envolvimento versus distanciamento, conceitos tidos como fatores centrais no esquema de Oesterreicher, segundo Marcuschi. (Urbano, 2006, p. 36)

No esquema elaborado por Oesterreicher (1986), a perspectiva do meio apresenta a distinção entre fônico e gráfico, que constitui uma noção dicotômica. Já a perspectiva da concepção não apresenta esse caráter dicotômico, mas gradual ou um continuum (Cf Marcuschi, 2001), limitado por dois extremos: imediatez comunicativa e distância comunicativa. Esse continuum pode ir da conversação face a face, que seria o prototípico da imediatez comunicativa, ao código jurídico, que seria o prototípico da distância comunicativa.

Briz Gómez e Serra Alegre (1997) afirmam que, aparentemente, há um paradoxo entre fala e escrita, no entanto, frequentemente, o falado aparece no escrito e o escrito está presente no falado; as interrelaçóes entre o falado e o escrito surgem como modos de verbalização determinados por condiçóes de comunicação, por isso antes de ser, propriamente, oposição, há um continuum gradual quando nos referimos náo ao meio, mas aos modos de realização do oral e do escrito (concepção). Essa diversidade está relacionada com as condiçóes de produção e recepção dos discursos (relação de proximidade entre locutor e interlocutor, saber e experiências compartilhados, assuntos do cotidiano, grau de planejamento, finalidade da comunicação), com as características dos interlocutores (competência linguística e cultural) e características do tipo de discurso. Esses parâmetros, que atuam de forma conjunta e interrelacionada, chegam a definir tipos, gêneros ou subgêneros discursivos dentro do oral e do escrito.

2 O termo concepção está ligado ao verbo conceber, dar à luz. 
Bustos Tovar (1997, p. 8) afirma que oralidade e escrituralidade não são termos antagônicos, a não ser pelos dois extremos de uma gradação que compreende desde a escrituralidade pura (emissão, recepção e organização textual correspondente à máxima distância comunicativa e meio gráfico) à oralidade pura (imediatez comunicativa e transmissão fônica). Há zonas intermediárias, em que a situação é, mais ou menos, híbrida, nas quais há elementos próprios da escrituralidade e elementos próprios da oralidade. Ao fazer consideraçôes sobre conversaçóes espontâneas e diálogos construídos, Bustos Tovar (1997, p. 20-22) assevera que, no plano da enunciação, a característica diferenciadora entre ambos se acha na estrutura interlocutiva e se manifesta em dois aspectos principais: $o$ modo em que se fazem presentes os interactantes e o funcionamento dos marcadores discursivos. $\mathrm{Na}$ conversação face a face, não existe necessidade de marcar as mudanças de turno de forma concreta e linguística, pois, em geral, são marcadas por elementos tonais ou gestuais. Nos diálogos construídos, a sequência do discurso está ordenada de acordo com a regulamentação canônica. A aparente liberdade com que falam as personagens, em clara imitação da conversação face a face, está, na realidade, planejada para obter um valor comunicativo que vai mais além do próprio diálogo. No plano do enunciado, as diferenças são mais notáveis. Nas conversações face a face, é difícil encontrar fluidez sintática, pois a característica principal é a suspensão do enunciado, que se torna interrompido na sua estrutura sintática de maneira constante. $\mathrm{Na}$ maior parte dos casos, não seria possível "reconstruir" a coerência gramatical, pois a construção verbal não seria interpretável não fosse pelo valor referencial de certos signos léxicos e fraseológicos que podemos associar com valores pragmáticos reconhecíveis socialmente. $\mathrm{O}$ mesmo ocorre com certos sinais de valor anafórico, cujo significado referencial não está só no diálogo, mas também no tipo de relação que se acha estabelecida entre os agentes do discurso.

\section{ANÁLISE DA CONVERSAÇÃO E MARCAS DE ORALIDADE NOS DIÁLOGOS CONSTRUÍDOS}

No Brasil, a década de 1990 foi bastante frutífera nos estudos conversacionais. Os diversos trabalhos teóricos dessa década enfrentaram a difícil tarefa de conceituar o termo conversação. Marcuschi (1988, p. 319-320) afirma que conversação será entendida "como uma interação centrada da qual participam pelo menos dois interlocutores que se revezam, tomando cada qual pelo menos uma vez a palavra, dando-se o evento comunicativo em uma identidade temporal". No mesmo estudo, Marcuschi (1988, p. 322) esclarece que o termo conversaçâo pode ser tomado 
em sentido amplo, abrangendo todas as formas de interação: "entre médicos e pacientes, no tribunal, em sessóes de terapia, na escola, nos aconselhamentos, nas entrevistas, na interação intercultural, interétnica”.

Fundamentados em Vigara Tauste (2000), Leite et alii (2010) fazem consideraçóes importantes sobre a conversação:

Durante a conversação, os interactantes falam conforme vão surgindo as ideias, segundo o que vão ouvindo de seus interlocutores, segundo as mudanças de interesses ou objetivos, segundo a percepção pontual do contexto. Para o desenvolvimento do tópico discursivo, o falante considera, constantemente, seu(s) interlocutor(es) (representaçôes, reaçôes, intençôes, expectativas, grau de intimidade, grau de concordância/discordância). Isso significa que, quando se interage com alguém, independentemente do tipo de interação, esse alguém é, em todos os sentidos, parte essencial do discurso resultante e do ato comunicativo realizado. (Leite et alii, 2010, p. 59)

Fávero et alii (2010, p. 93) afirmam que a conversação é "um processo interacional específico, que implica participação conjunta dos interactantes na dinâmica evolutiva de um evento comunicativo informal, localmente processado". Hilgert (2001, p. 65) salienta que o texto conversacional caracteriza-se por ser processo e não produto, isto é, o texto falado, propriamente dito, constitui-se no próprio ato de produção. Dessa forma, o planejamento do que dizer e a formulação desse dizer não são etapas que se sucedem, mas são simultâneas, por isso mesmo são frequentes as descontinuidades, pois o fluxo da informação não ocorre de forma fluente e continuada. Com isso, são comuns hesitaçôes, segmentos cortados, reformulações, silêncios, marcadores conversacionais, sobreposição de vozes.

Como já foi explicitado no início, nosso corpus é constituído por textos literários. Não podemos nos esquecer de que os diálogos literários nada mais são do que uma tentativa de reproduzir a realidade. Negreiros (2009, p. 68-69) observa que o escritor se vale de "certos recursos orais na elaboração do texto artístico escrito, o que é uma forma de criação de uma realidade linguística ilusória”. Vale lembrar, ainda, as consideraçóes de Urbano:

A artificialidade patenteia-se, em primeiro lugar, por ser uma língua "escrita", condicionada, pois, às técnicas próprias da língua escrita, passa depois pela estruturação narrativa planejada e termina por uma linguagem estilizada. Os diálogos, por exemplo, que na língua falada espontânea diária nascem e se desenvolvem muitas vezes ao 
sabor das situações e alheios à vontade dos falantes, têm, na língua literária, sempre propósitos definidos pelo autor/narrador, embora dando uma ilusão contrária. (Urbano, 2000, p. 129).

Apesar de entender o diálogo literário ou diálogo construído como uma criação estética, é importante salientar que o escritor considera a realidade à sua volta para construir os seus diálogos. Para comprovar, basta verificar que os mecanismos de organização das conversações espontâneas são encontrados também nos diálogos construídos. Preti (2001, p. 218), entretanto, ressalva que, por mais que o escritor busque se aproximar da naturalidade da fala, o diálogo construído pressupóe elaboração prévia. Trata-se, portanto, de uma naturalidade elaborada.

Com efeito, no processo de criação literária, entram em jogo os dois planos da linguagem: oralidade e escrituralidade. No plano discursivo, observa-se que o discurso da escrituralidade e da oralidade têm características comuns e outras que os separam. Se analisarmos a natureza discursiva dos diálogos construídos, é fácil observar que, com respeito à concepção, o diálogo construído se acha em uma posição intermediária entre oralidade e escrituralidade, pois não deixa de apresentar uma série de características que encontramos nas conversações face a face, gênero prototípico da oralidade. Por outro lado, é inegável que, com respeito ao meio, o diálogo construído está na esfera da escrituralidade, pois o meio gráfico é a forma pela qual os leitores conhecerão os diálogos estabelecidos entre as personagens.

Para Hilgert (2009, p. 217-218), a oralidade pode aparecer em diferentes graus em diferentes gêneros e "até, ao menos em tese, estar totalmente ausente, o que determinaria textos com um grau máximo de escrituralidade”. Ressalta, também, que diversos textos escritos, que incorporam traços que evocam as condiçôes de produção próprias de um texto falado, são marcados pela oralidade.

\section{EFEITOS DE ORALIDADE EM TEXTOS ESCRITOS}

Fundamentados nas características da oralidade, consideradas por Oesterreicher (1996), Briz Gómez e Serra Alegre (1997), Bustos Tovar (1997), Briz Gómez (1998), Barros (2000), Hilgert (2000), Marcuschi (2001) e Urbano (2000 e 2006), selecionamos alguns aspectos da oralidade para tecermos comentários que possam ser úteis aos professores em sala de aula, tanto para analisarem textos literários de autores contemporâneos, quanto para analisarem e avaliarem textos escritos por alunos nas aulas de língua portuguesa. 


\subsection{Presença de pares adjacentes para iniciar, fomentar ou encerrar o tópico}

De acordo com Marcuschi (1986), pares adjacentes, como o próprio termo indica, são sequências de dois turnos integrados. Tais sequências podem ser saudação/ saudação, convitelaceitação/recusa; agradecimentolaceitação; perguntalresposta. Este último é o mais frequentes nas conversas.

Na crônica "Suflê de chuchu", a jovem, repentinamente, foi viver na França. Sem que a família soubesse, ela, que nunca se envolvera em qualquer trabalho doméstico, estava trabalhando como empregada doméstica.

Exemplo $1^{3}$

T1 (filha) - Não posso falar muito, mãe. Como é que se faz café?

T2 (mãe) - O quê?

T3 (filha) - Café, café. Como é que se faz?

T4 (mãe) - Não sei, minha filha. Com água, com... Mas onde é que você está, Duda?

T5 (filha) - Estou trabalhando de "au pair" num apartamento. Ih, não posso falar mais. Eles estão chegando. Depois eu ligo. Tchau

Comédias para se ler na escola, "Suflê de chuchu", p. 29

Trata-se do primeiro telefonema depois da viagem. Repare-se que o tópico é iniciado e mantido por meio de pares adjacentes (pergunta e resposta): T1, T2, T3 e T4. É um processo muito comum na língua falada e, em especial, nas conversaçóes.

Além dos pares adjacentes, também é frequente a presença das sequências inseridas, isto é, um par adjacente entre duas partes de outro par adjacente, como se pode notar no exemplo a seguir.

Exemplo 2

T1 (empregada) - Dr. Anselmo, eu...

T2 (patrão) - Não me chame de doutor. Anselmo, Anselmo.

T3 (empregada) - Anselmo, eu...

T4 (patrão) - Tocão.

T5 (empregada) - Como?

3 Para facilitar os comentários, optou-se por enumerar os turnos (T), isto é, as falas das personagens. Quando for necessário, serão acrescentadas informaçóes sobre as personagens, como neste exemplo: filha e mãe. No final de cada exemplo, estão indicados, respectivamente, o título da obra, o título da crônica e a página onde se encontra. 


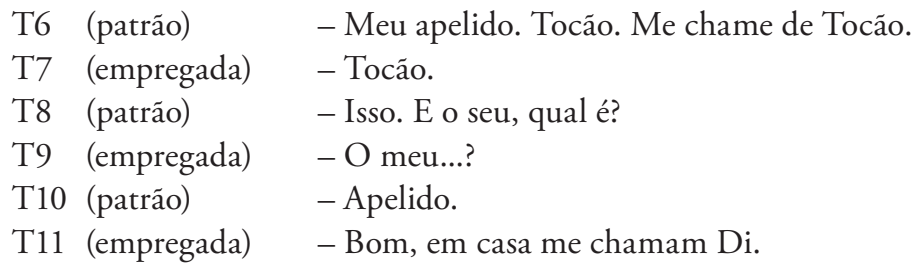

Amor Veríssimo, "Confraternizaçáo", p. 185

Como o próprio título indica, patrão e empregada se encontram em uma festa de confraternização da empresa. O patrão, Dr. Anselmo, já bebeu demais, por isso deseja deixar as formalidades de lado na relação com sua empregada. Entre os turnos 9 e 10, temos um exemplo típico de sequência inserida. Repare-se que, no turno 8, há a primeira parte do par adjacente, a pergunta ("E o seu, qual é?"), que só é respondida no turno 11 ("Bom, em casa me chamam Di"). Entre os turnos 9 e 10, há outro par (primeira parte - pergunta - "O meu..." e segunda parte - resposta - "'Apelido"). A esse tipo de estrutura, comum nas conversaçóes, dá-se o nome de sequência inserida.

\subsection{Temas próprios do cotidiano, isto é, temática não especializada}

Nas conversaçóes face a face, predominam temas próprios do cotidiano, isto é, temas que estejam de acordo com conversaçóes espontâneas e descompromissadas. Algumas vezes, percebe-se que o importante não é o aspecto referencial, isto é, o assunto da conversa, pois mais importante do que veicular informaçóes é o interagir.

Exemplo 3

T1 (Ele) - Não, pode ficar. Quem sabe a gente já abre o vinho e fica bebericando, enquanto eu...

T2 (Ela) - Adoro bebericar. Uma beleza, o seu abridor.

T3 (Ele) - Obrigado. Este vinho precisa respirar um pouco antes de ser servido. Pode parecer bobagem, mas...

T4 (Ela) - Não, não. Respirar é das coisas mais importantes que existem.

T5 (Ele) - Ele precisa estar na temperatura ambiente.

T6 (Ela) - Adoro temperatura ambiente.

T7 (Ele) - Você está disposta a experimentar o meu bobó?

Sexo na cabeça. "Uma história sutil", p. 23 
A crônica em questão relata o encontro entre um homem e uma mulher. Ele a convida para jantar e o cardápio a ser servido será bobó de camarão. Enquanto prepara o jantar, ele abre a garrafa de vinho. Talvez o clima do encontro e a timidez provocada pelo encontro levem a jovem a não desenvolver, propriamente, conteúdo referencial, pois o importante é a interação e não a veiculação de informaçôes. É fácil perceber isso, por meio de lugares-comuns, como "Adoro bebericar. Uma beleza o seu abridor" (T2), "Respirar é das coisas mais importantes que existem.” (T4), "Adoro temperatura ambiente." (T6). Em T7, percebe-se, claramente, que os temas são corriqueiros, como provar o bobó de camarão.

\subsection{Interação face a face entre, pelo menos, dois interlocutores que se situam em mesmos campos dêiticos pessoais, locais e temporais e que partilham de um mínimo de conhecimentos comuns.}

Exemplo 4

T1 (Ele) - Água doce. Marinheiro de água doce. Você quer esperar na sala, enquanto eu...

T2 (Ela) - Fico aqui com você. A menos que...

T3 (Ele) - Não, pode ficar. Quem sabe a gente já abre o vinho e fica bebericando, enquanto eu...

T4 (Ela) - Adoro bebericar. Uma beleza, o seu abridor.

T5 (Ele) - Obrigado. Este vinho precisa respirar um pouco antes de ser servido. Pode parecer bobagem, mas...

T6 (Ela) - Não, não. Respirar é das coisas mais importantes que existem.

Sexo na cabeça. "Uma história sutil”, p. 23

Nos textos prototípicos da oralidade, como são as conversações espontâneas, há uma relação vivencial de proximidade entre os interlocutores, cuja consequência imediata leva ao saber e à experiência compartilhados. $\mathrm{O}$ fragmento apresenta a que ponto chega a interação conversacional, pois, ainda que não complete o pensamento e a verbalização deste, o interlocutor entende perfeitamente o que seria enunciado por causa do conhecimento partilhado. A conversação flui de forma bastante espontânea, com interrupçóes de ambas as partes. Sacks, Schegloff e Jefferson (1974) deixam evidente que a regra básica da conversação é "fala um de cada vez". Em um diálogo espontâneo, frequentemente, essa regra é violada, sem, no entanto, trazer prejuízo à interação. Observe-se, também, que há o que os analistas da conversação chamam de assalto ao turno (Galembeck, Silva 
e Rosa,1990 e Galembeck, 1993), isto é, um locutor toma a palavra sem que o outro tenha finalizado. Constantemente, isso ocorre porque, quando um entende o que o outro quer dizer, não há necessidade de finalizar o conteúdo referencial.

No primeiro e no segundo turno, houve interrupçóes porque os interlocutores haviam entendido o que o outro diria. Repare-se, também, que a locutora, seja por nervosismo, seja por vontade de interagir, acaba interrompendo com o desejo intenso de participar, como ocorre em T6, em que ela não deixa o interlocutor finalizar o segmento e interfere. $\mathrm{O}$ "não, não" é uma negação do último segmento do locutor que havia dito "Pode parecer bobagem". Ela discorda e afirma que "respirar é uma das coisas mais importantes que existem". Ocorre o que Galembeck, Silva e Rosa (1990) chamam de assalto com deixa, isto é, não houve uma interrupção brusca. A "deixa" é representada pela pausa de hesitação (reticências no final de T5).

\subsection{Simultaneidade entre planejamento e produçáo com as marcas características: descontinuidade sintática, desvios, construçóes interrompidas ou abandonadas}

Já mencionamos que, na esfera da oralidade, planejamento e formulação são quase simultâneos. Quando escrevemos, buscamos planejar previamente não só o tema a ser desenvolvido, mas também o aspecto linguístico-discursivo. Quando falamos, ainda que possa haver planejamento temático, em geral, não há planejamento linguístico-discursivo, pois o fluxo informacional ocorre on-line, isto é, no instante em que está sendo formulado. Em outras palavras, planejamento e execução se confundem, por isso há descontinuidades que acarretam falhas na formulação, evidenciadas por hesitaçóes, segmentos interrompidos, incompletos ou abandonados.

Vejamos alguns exemplos desse caráter de status nascendi, próprio da oralidade.

\section{Exemplo 5}

T1 - Como é que ela estava vestida?

T2 - Shorts.

T3 - Ai!

T4 - Chegamos atrás dos cômoros e começamos a conversar...

T5 - Corta os créditos e o diálogo. Chega ao principal.

T6 - Não houve.

T7 - O quê?

T8 - Na hora eu... eu... 
T9 - Conta!

T10 - Comecei a chorar.

Sexo na cabeça, "Emoçâo", p. 39

Nesta crônica, os amigos estavam ansiosos para saber como fora o encontro entre Pio e Débora, que era uma jovem muito bonita e atraente. Na primeira resposta (T2), é possível perceber o dinamismo próprio da oralidade. Não há necessidade de Pio responder aos amigos desta forma: "Débora estava vestida de shorts". O simples enunciado "shorts" comunica e satisfaz os que esperam ansiosamente pela resposta. Em T3, há um exemplo de turno inserido interacional (Galembeck, Silva e Rosa, 1990), cuja função é demonstrar reação ao que é enunciado. Há a expressão do suspense e da expectativa diante da narração de Pio. Em T5, o amigo pede agilidade na narração dos fatos e que Pio suprima o que é supérfluo (“Corta os créditos e o diálogo. Chega ao principal."). Diante da decepção, Pio hesita no que vai falar aos amigos, por isso aparece um problema de formulação: "Na hora eu... eu..." (T8). Esse tipo de corte no enunciado é muito comum na esfera da oralidade, contudo não costuma aparecer no âmbito da escrituralidade. Diante da hesitação de Pio, o amigo insiste, com certa expectativa: "Conta." (T9). Para a decepção dos amigos, vem a complementação em T10: "Comecei a chorar". Ressalte-se que o enunciado que se inicia em T8 é completado em T10, como se fosse um todo e único segmento sintático. Essa é a dinâmica própria da oralidade.

Cabe ao professor esclarecer os seus alunos a respeito das especificidades de cada gênero. Como se trata de um diálogo construído, busca-se reproduzir a realidade própria da oralidade, ainda que seja transmitida por meio gráfico.

\section{Exemplo 6}

T1 - Aí o anãozinho pega o desentupidor de pia e...

T2 - Sim?

T3 - E... e... Como é mesmo? Já me vem...

T4 - Não!

\section{Comédias para se ler na escola, "Anedotas", p. 108}

Esta crônica se refere a dificuldades de se criar e de contar anedotas. O fragmento em questão aborda a situação incômoda de começar a contar a anedota e não se lembrar da continuação. No primeiro turno (T1), o contador de anedota inicia a narração, mas se esquece de como continua. Na escrita, a hesitação 
é representada por meio das reticências. Como, de fato, ocorre na oralidade, o interlocutor procura animar o contador de anedotas, demonstrando que está atento e à espera da continuação. Isso é evidenciado em T2 por meio da indagação "Sim?”, isto é, vá em frente, continue. Em T3, evidencia-se a hesitação: “E... e...". O planejamento local também fica estampado na pergunta "Como é mesmo?”. Esse tipo de indagação não é destinado ao interlocutor, pois, na verdade, o locutor tenta lembrar-se e, como não consegue, faz uma pergunta a si mesmo, como se fosse uma estratégia para reavivar a memória. No mesmo turno (T3), o locutor, já desesperado, rende-se à falha da memória e diz para o interlocutor que, em breve se lembrará (“Já me vem..."). Trata-se de uma forma atenuada de reconhecer a falha e admitir o desastre de não poder contar a anedota.

Exemplo 7

T1 (Ela) - Beleza, a sua cozinha.

T2 (Ele) - Obrigado, eu...

T3 (Ela) - É você quem cozinha sempre ou...

T4 (Ele) - Não, não. Tem uma senhora que vem arrumar o apartamento sempre e deixa um prato feito na geladeira. Sou cozinheiro de fim de semana. Marinheiro de... Como é mesmo que se diz?

T5 (Ela) - O quê?

T6 (Ele) - Doce.

T7 (Ela) - Eu?

T8 (Ele) - Água doce. Marinheiro de água doce. Você quer esperar na sala, enquanto eu...

T9 (Ela) - Fico aqui com você. A menos que...

Sexo na cabeça, "Uma história sutil", p. 23

O primeiro aspecto a ser observado está em T1: a ordem das palavras não segue o padrão da escrituralidade. Caso fôssemos passar para algum gênero típico dessa esfera, a ordem, certamente, seria outra, como, por exemplo, "A sua cozinha é uma beleza." Além do mais, percebe-se que a interação domina a dinâmica da oralidade, pois em T3, não há necessidade de completar o que seria dito, pois o referente comum faz com que haja economia de palavras. Em T4, percebemos, em primeiro lugar, o termo coloquial "ter" no lugar de "haver". Em seguida, a ordem das palavras próprias da oralidade, o advérbio sempre deveria, no âmbito da escrituralidade, preceder o verbo "Há uma senhora que sempre vem arrumar...". Além desses aspectos mencionados, encontra-se um exemplo primoroso da falta de planejamento prévio. Ele não consegue se lembrar do termo "Marinheiro de 
água doce”, por isso pede ajuda à interlocutora, que, por sua vez, também não entende a dificuldade, por isso acaba ocasionando o equívoco, quando ele se lembra de parte do segmento - "doce" (T6) e ela pensa que está sendo elogiada (T7).

No caso dos diálogos construídos, é evidente que o escritor é o responsável pelo texto produzido, mas quem age são as personagens. Há tal preocupação do escritor em representar os aspectos enunciativos da conversação que, em nosso corpus, há vários exemplos dessa dinâmica. No exemplo a seguir, retirado da crônica "Tesouro", há a reprodução do diálogo entre dois idosos que conversam a respeito das mulheres mais jovens. Observe-se que há diálogos puros, sem qualquer interferência do narrador, como se fosse uma transcrição de um diálogo entre dois informantes. Cada turno é marcado pelo travessão.

\section{Exemplo 9}

Dois velhos sátiros conversando. Sobre as menininhas.

T1 - Que safra.

T2 - Grande safra.

T3 - Cada neném...

T4 - Nem me fala.

T5 - Lindas.

T6 - E desinibidas.

T7 - Desinibidas. Sem preconceitos.

T8 - Informais.

T9 - Nenhuma chama a gente de senhor.

T10 - Agora, tem uma coisa...

T11 - O quê?

T12 - Não sei se acontece isto com você, mas às vezes...

T13 - O quê?

T14 - Falta papo. É ou não é?

T15 - Como assim?

T16 - Sei lá. Está certo que o que a gente procura nelas não é estímulo intelectual.

Mas de vez em quando a gente gosta de... não é mesmo? Conversar. Trocar ideias.

T17 - Nem que seja só para recuperar o fôlego.

T18 - Exato. E não dá. Esta geração não leu nada.

T19 - Nada.

Sexo na cabeça, "Tesouro", p. 37

Ainda que seja um diálogo construído, há marcas evidentes da interação que há nas conversaçóes face a face. Somente a partir do conhecimento 
partilhado, é possível entender o tópico desenvolvido. A partir do terceiro ou do quinto turno, entende-se que os interlocutores estão falando a respeito da safra de jovens bonitas. Percebe-se a co-construção do texto conversacional. O turno de um vai completando o turno do outro, como se fosse uma única fala. Conforme ressalta Galembeck (2009, p. 251), as "oraçôes se sucedem sem um plano definido, e não possuem limites nítidos, como ocorre na escrita padrão". Por esse motivo, "o conceito canônico de frase (tal como se manifesta na realização escrita) é de difícil aplicação na fala". Isso mostra o alto grau de envolvimento interpessoal, que é uma das características marcantes da oralidade. Seguindo a classificação de Galembeck, Silva e Rosa (1990), encontramos turnos nucleares (aqueles que têm valor referencial e fazem avançar o tópico) e turnos inseridos (aqueles que não fazem avançar o tópico, mas apresentam a importante função de concordância, aceitação e monitoramento, como em T4 - "Nem me fala" e em T19 - "Nada."). A interação entre as personagens é tal, que o discurso é co-construído também em nível sintático. O quinto turno se une, sintaticamente, ao sexto, ao sétimo e ao oitavo como se fosse uma única fala.

Nos turnos 11 e 13, verifica-se outra característica marcante da oralidade, os problemas de formulação. A personagem, ao mesmo tempo, fala, planeja e reflete, por isso não deixa claro o que está, de fato, querendo dizer ("Agora, tem uma coisa..." e "Não sei se acontece isto com você, mas às vezes..." e "Falta papo. É ou não é?"). A falta de entendimento leva o interlocutor a manifestar-se: "O quê?" (T11 e T13) e "Como assim?" (T15). Dessa forma, esclarece-se qual era a preocupação do interlocutor: as jovens são bonitas e atraentes, mas não são cultas, por isso a conversa não flui. Também, aparecem os problemas de planejamento que emergem no ato da enunciação. Como não tem certeza do que está dizendo, o interlocutor enuncia "Sei lá", pois está na dúvida do que vai ser dito. Tudo isso está ligado ao início da conversa: a beleza física das jovens, que, ao longo da conversa passa a ser questionada pela falta de cultura.

Ainda em referência à falta de fluidez sintática, é interessante citar as correçôes que são comuns no âmbito da oralidade. Barros (2001, p. 136) conceitua correção como "um procedimento de reelaboração do discurso que visa a consertar seus 'erros" e "erro" é entendido como uma escolha inadequada do falante. Tal escolha pode ser lexical, sintática, prosódica, de organização textual ou conversacional. Neves (2009, p. 29) assevera que o indivíduo que fala tem consciência de que todo segmento já enunciado foi recebido pelo interlocutor e qualquer "erro" - no sentido acima referido - pode ser corrigido face a face na presença do interlocutor. Entretanto, quando se escreve, "(só) pode reparar seu texto em privacidade. Isso tem a ver, ainda, com as diferentes condiçôes e oportunidades de planejamento verbal em cada uma das modalidades." Neves (2009, p. 29) 
também esclarece que, no âmbito da oralidade, quando se corrige, deseja-se, de fato, corrigir; enquanto, no âmbito da escrituralidade, quando se corrige, desejase obter algum efeito estilístico. Vejamos os exemplos a seguir.

Exemplo 10

T1 (jornalista) - Sua cor favorita.

T2 (entrevistado) - Verde. Não! Azul!

T3 (jornalista) - Vamos, Rudi. É verde ou é azul?

T4 (entrevistado) - Azul, azul!

T5 (jornalista) - Quem você levaria para uma ilha deserta?

T6 (entrevistado) - Não sei. Me deixem pensar.

T7 (jornalista) - "Pensar", Rudi? "Pensar"?! Você acha que está respondendo para o suplemento cultural? Vamos, quem você levaria para uma ilha deserta?

Dalva registrou com surpresa que Sandrinha é que fizera a pergunta. Rudi respondeu.

T8 (entrevistado) - A minha mãe. Não. A Malu Mader

Comédias para se ler na escola, "A novata", p. 81

Nesta crônica, o editor deseja testar a capacidade da jornalista novata, a Sandrinha, por isso pede para outra jornalista, a Dalva, mais experiente, levá-la para uma entrevista. A jornalista experiente começa a fazer uma série de perguntas ao entrevistado, Roni. Este, sob pressão, não tem tempo de pensar, refletir e planejar o que vai responder. Por causa disso, comete os referidos "erros" e, percebendo que havia cometido tais "erros", busca corrigi-los. No primeiro exemplo de correção (T2), o entrevistado se equivoca e, no lugar de enunciar "azul”, acaba enunciando "verde". Em seguida, corrige e anuncia tal correção por meio do segmento não. Repare-se que, em T4, para reiterar a correção, acaba repetindo o segmento correto: “Azul, azul!". No segundo exemplo (T8), procede da mesma forma, usando também a negação.

Exemplo 11

T1 (filho) - Sexo não tem feminino?

T2 (pai) - Não.

T3 (filho) - Só tem sexo masculino?

T4 (pai) - É. Quer dizer, não. Existem dois sexos. Masculino e feminino.

T5 (filho) - E como é o feminino de sexo?

T6 (pai) - Não tem feminino. Sexo é sempre masculino.

(...) 
T7 (filho) - O sexo da mulher é igual ao do homem?

T8 (pai) - É. Quer dizer... Olha aqui. Tem o sexo masculino e o sexo feminino, certo?

Comédias para se ler na escola; "Sexa”, p. 53-54

O fragmento em questão traz dois casos de correção. O filho questiona o pai a respeito do termo sexo. Na verdade, o filho acha que, para o masculino deve ser sexo e, para o feminino, sexa. As perguntas do filho deixam o pai confuso, por isso, ao responder, percebe que cometera os equívocos. Nos dois casos, há o que, na Análise da Conversação, se costuma chamar de marcador de reformulação quer dizer - que anuncia que haverá uma reformulação.

\subsection{Expressóes coloquiais e marcadores de envolvimento[}

Barros (2006, p. 65) ressalta que, considerando a concepção de norma, há diferenças quando se comparam oralidade e escrituralidade, pois, no âmbito da oralidade, "são aceitos usos considerados insuficientes na escrita como, por exemplo, a linguagem dita popular ou mesmo coloquial.” Também, é importante ressaltar as observaçóes de Preti (2004)

Além disso, no contexto político-social do Brasil contemporâneo, a linguagem popular, o vocabulário gírio, o estilo comum da mídia romperam as expectativas do leitor e se instalaram também na ficção literária, com artifícios de linguagem que lembram a interação espontânea oral face a face, com sua variação de registros, com a mudança abrupta dos tópicos e subtópicos da conversação, com recursos novos para descrever o hábil jogo de preservação das faces dos interlocutores. (Preti, 2004, p. 120)

Exemplo 12

T1 - Tou te estranhando, André.

T2 - Por quê?

T3 - Estamos neste carro há meia hora e você não me deu uma cantada.

T4 - Pois é.

Pois é"?! O que queria dizer "Pois é"? E aquele tom sombrio?

T5 - Sou eu, é? Eu não sou mais cantável?

T6 - Não. Quié isso. Você continua linda. É que, sei lá. Desisti. 
T7 - Ainda bem. Porque você sabe que era um chato, não sabe?

T8 - Sei, sei.

Ela examinou seu rosto. Perguntou:

T9 - Você está com algum problema de saúde?

T10 - Não, não.

T11 - O que é então?

T12 - É tudo, entende? Tudo. Desisti de tudo.

Sexo na cabeça, "Estranhando o André", p. 66

O fragmento acima traz alguns exemplos claros de termos coloquiais e marcadores de envolvimento. Em T1, há o emprego da forma "Tou", muito comum na fala espontânea; em T4, o marcador "Pois é", que indica concordância e conformismo; em T6, a forma "Quié", buscando representar como a personagem, de fato, estaria falando; em T7, o marcador de envolvimento "não sabe?"; em T8 e T10, a repetição enfática: "sei, sei" e "Não, não"; em T12, outra ocorrência de marcador de envolvimento: "entende?”.

\section{Exemplo 13}

T1 - Será que não há mesmo outro jeito?

T2 - Bem, se você quer ver nos jornais a história de como você roubava material do seu gabinete para vender...

T3 - Ssssh!

T4 - Nunca entendi. Você não se contentava com seu salário de...

T5 - Ssssh!

T6 - Tinha de vender os clipes de papel?!

T7 - E você? E você?

T8 - O que que tem eu?

T9 - E o cabaré no porão do minis...

T10 - Ssssh!

Comédias para se ler na escola, "Pode acontecer", p. 88

Neste fragmento, encontramos algumas ocorrências evidentes de oralidade. Em primeiro lugar, Há que ressaltar a forma "Ssssh!" de T3, T5 e T10. Tratase de um elemento não lexicalizado e que serve para pedir silêncio ou falar mais baixo, a fim de não divulgar algo que se pretende manter como segredo. Em T8, encontramos uma estrutura sintática típica da oralidade e, em geral, condenada pelos professores quando repetida em gêneros do âmbito da escrituralidade: 
“Que que tem eu?”. Em T9, encontramos um caso típico de assalto ao turno sem "deixa", isto é, uma interrupção brusca na fala do interlocutor. Tal interrupção se deve ao fato de que o indivíduo que interrompe não deseja, em hipótese alguma, que tal fato seja divulgado.

Para finalizar, gostaria de registrar alguns fragmentos com marcadores conversacionais que, frequentemente, também aparecem nos textos escritos pelos alunos nas aulas de língua portuguesa. De uma forma diferente dos demais exemplos, reunirei os fragmentos sob a chamada do Exemplo 14, mas com a ressalva de que se trata de fragmentos de crônicas distintas. As ocorrências próprias da oralidade estáo assinaladas em negrito.

Exemplo 14

T1 - Tira você mesmo, ué.

T2 - Ah, é? E eu não saio na foto (Comédias para se ler na escola, "A foto", p. 37)

T1 - Eu estava ali agora mesmo, tomando um cafezinho, quando chega o Túlio. Conversa vai, conversa vem e coisa e tal e pá, pá, pá...

Eu e a americana nos entreolhamos.

T2 - Funciona como reticências - sugeri eu. __ Significa, na verdade, três pontinhos. "Ponto, ponto, ponto."

T3 - Mas por que "pá" e não "pá”? Ou "pi" ou "pu”? Ou "etcétera"? (Comédias para se ler na escola, "Pá, pá, pá”, p. 57

T1 - Os hermeneutas estão chegando!

T2 - Ih!, agora é que ninguém vai entender mais nada... (Comédias para se ler na escola, "Defenestração", p. 59)

T1 - Querida...

T2 - Mmmm?

T3 - Há uma coisa que eu preciso lhe dizer... (Comédias para se ler na escola, "Defenestração", p. 59

\section{CONSIDERAÇÓES FINAIS}

Com este estudo, busquei retomar aspectos teóricos básicos a respeito das relações entre fala e escrita e mostrar como, de fato, há efeitos de oralidade em textos escritos, em especial nos diálogos literários construídos. 
Tive, como foco principal, o trabalho do professor de língua portuguesa na sala de aula, pois, por meio de uma rápida observação - que não chega a ser uma análise propriamente dita - das atividades de oralidade propostas nos livros didáticos que circulam nas escolas brasileiras, comprova-se uma triste constatação: há conhecimento teórico consistente a respeito do assunto, entretanto há, também, uma grande lacuna entre teoria e prática. Os professores de língua portuguesa continuam a ter dificuldades em propor atividades práticas que levem seus alunos a uma reflexão consistente sobre oralidade.

Estou consciente de que este trabalho está, ainda, por completar-se e que há muito por fazer. Talvez, um trabalho específico sobre a prática na sala de aula pudesse ser levado a cabo por especialistas preocupados com a qualidade do ensino de língua materna.

\section{REFERÊNCIAS}

Areta Lara M. Reflexiones sobre la presencia de lo oral en declaraciones matrimoniales de finales del siglo XVI. In: Cortés Rodrigues L, et al. (Coords.). Oralia. Anejo 3/1. Discurso y oralidad. Madri: Arco/Libros; 2007. p. 317-331.

Barros DLP. Entre a fala e a escrita: algumas reflexôes sobre as posiçóes intermediárias. In: Preti D (Org.). Fala e escrita em questão. São Paulo: Humanitas; 2000. p. 57-77.

Barros DLP. Procedimentos de reformulação: a correção. In: Preti D (Org.). Oralidade em textos escritos. São Paulo: Humanitas; 2001. p. 129-156.

Barros DLP. Efeitos de oralidade no texto escrito. In: Preti D (Org.). Oralidade em diferentes discursos. São Paulo: Humanitas; 2006. p. 57-84.

Briz Gómez A. El español coloquial en la conversación: esbozo de pragmagramática. Barcelona: Ariel; 1998.

Briz Gómez A. Aportaciones del análisis del discurso oral. In: Sánchez Lobato J, Santos Gargallo I (Orgs.). Vademécum para la formación de profesores. Madri: Sociedad General Espańola de Librería (SGEL); 2004. p. 219-242.

Briz Gómez A, Serra Alegre E. De lo oral y lo escrito y entre lo oral y lo escrito. In: Briz Gómez A, Cuenca Ordinyana MJ, Serra Alegre E (Eds.). Sobre l'oral i l'escrit. Valencia: Universitat de València; 1997. p. 1-6. 
Bustos Tovar JJ. La imbricación de la oralidad em la escritura como técnica del discurso narrativo. In: Kotschi T, Oesterreicher W, Zimmermmann K (Eds.). El español hablado y La cultura oral en España e hispanoamérica. Madri: Iberoamericana; 1996. p. 359-374.

Bustos Tovar JJ. Organización textual y oralidad. In: Briz Gómez A, Cuenca Ordinyana MJ, Serra Alegre E (Eds.). Sobre l'oral i l'escrit. Valencia: Universitat de València; 1997. p. 7-24.

Fávero LL, et alii. Interação em diferentes contextos. In: Bentes AC, Leite MQ (Orgs.). Linguística de texto e análise da conversação: panorama das pesquisas no Brasil. São Paulo: Cortez; 2010. p. 91-158.

Galembeck PT. O turno conversacional. In: Preti D (Org.). Análise de textos orais. São Paulo: Humanitas; 1993. p. 55-79.

Galembeck PT. Marcas da oralidade em textos escolares. In: Preti D (Org.). Oralidade em diferentes discursos. São Paulo: Humanitas; 2009. p. 249-261.

Galembeck PT, Silva LA, Rosa MM. O turno conversacional. In: Preti D, Urbano H (Orgs.). A linguagem falada culta na cidade de São Paulo. São Paulo: T.A.Queiroz/ Fapesp; 1990. p. 58-98.

Hilgert G. A construçấo do texto "falado" por escrito: a conversação na internet. In: Preti D (Org.). Fala e escrita em questão. São Paulo: Humanitas; 2000. p. 17-55.

Hilgert JG. A qualificação discursiva no texto falado. In: Urbano H, et alii (Orgs.). Dino Preti e seus temas:oralidade, literatura, mídia e ensino. São Paulo: Cortez; 2001. p. 62-84.

Hilgert JG. A oralidade em textos escritos: reflexôes à luz de uma teoria de texto. In: Caleidoscópio. 2011;3(9):171-179.

Koch P, Oesterreicher W. Linguagem da imediatez - linguagem da distância: oralidade e escrituralidade entre a teoria da linguagem e a história da língua. Tradução do alemão de Hudinilson Urbano e Raoni Caldas. Linha D’Água. 2013[1985];26(1):153-174.

Leite MQ, et alii. A Análise da Conversação no Grupo de Trabalho Linguística do Texto e Análise da Conversação da Associação Nacional de Pós-Graduação em letras e 
Linguística. In: Bentes AC, Leite MQ (Orgs.). Linguística de texto e análise da conversação: panorama das pesquisas no Brasil. São Paulo: Cortez; 2010. p. 49-87.

Marcuschi LA. Análise da Conversação. São Paulo: Ática; 1986.

Marcuschi LA. Questões atuais na Análise da Conversação. 30 Encontro Nacional da ANPOLL;3.jul.1988; Recife, Brasil. Recife: ANPOLL; 1988. p. 319-335.

Marcuschi LA. Concepção de língua falada nos manuais de português de $1^{\circ}$. E $2^{\circ}$ graus: uma visão crítica. In: Trabalhos em Linguística Aplicada. 1997; 30:39-79.

Marcuschi LA. Da fala para a escrita: atividades de retextualização. São Paulo: Cortez; 2001.

Negreiros GRC. Marcas de oralidade na poesia de Manuel Bandeira. São Paulo: Paulistana; 2009.

Neves MHM. Fala e escrita: a mesma gramática? In: Preti D (Org.). Oralidade em textos escritos. São Paulo: Humanitas; 2009. p. 19-40.

Oesterreicher W. Lo hablado en lo escrito. Reflexiones metodológicas y aproximación a una tipología. In: Kotchi T, Oesterreicher W, Zimmermmann K (Eds.). El español hablado y La cultura oral en Espańa e hispanoamérica. Madri: Iberoamericana; 1996. p. $317-340$.

Preti D. A língua falada e o diálogo literário. In: Preti D (Org.). Análise de textos orais. 5.ed. São Paulo: Humanitas; 2001. p. 215-228.

Preti D. Estudos de língua oral e escrita. Rio de Janeiro: Lucerna; 2004.

Silva LA. Oralidade em contos de Luiz Vilela. In: Preti D (Org.). Oralidade em textos escritos. Sáo Paulo: Humanitas; 2009. p. 151-187.

Urbano H. Oralidade na literatura:o caso Rubem Fonseca. São Paulo: Cortez; 2000.

Urbano H. Usos da linguagem verbal. In: Preti D (Org.). Oralidade em diferentes discursos. São Paulo: Humanitas; 2006. p. 19-55.

Veríssimo LF. Comédias para se ler na escola. Rio de Janeiro: Objetiva; 2001. 
Filol. Linguíst. Port., São Paulo, v. 17, n. 1, p. 131-155, jan./jun. 2015

Veríssimo LF. Sexo na cabeça. Rio de Janeiro: Objetiva; 2002.

Veríssimo LF. Amor Veríssimo. Rio de Janeiro: Objetiva; 2013. 